\title{
Transverse vaginal septum: Management and outcomes
}

\author{
Monali Ashok Sonone ${ }^{1 *}$, G S Shekhawat ${ }^{2}$
}

1Post Graduate Resident, 2Professor \& HOD, Department Of Obstetric And Gynaecology, Smt. Kashibai Navale Medical College And Hospital, Narhe,Pune, Maharashtra, INDIA.

Email: dr.monaliasonone@gmail.com

\begin{abstract}
Background: To examine the management and outcomes of transverse vaginal septae. Design: descriptive observational study and retrospective data. Setting: Tertiary referral centre SMT. KASHIBAI NAVALE MEDICAL COLLEGE and HOSPITAL, Narhe, Pune. Population of 22 girls and women with a transverse vaginal septum. Methods: Data from medical records of all cases (2012-2019) of transverse vaginal septae were collected and reviewed. Main outcome measures: Presentation, examination findings, investigations, surgery, and long-term reproductive outcomes. Results: The septae in the study were described as follows: $64 \%$ were imperforate, and presented with obstructed menstruation; $36 \%$ were perforate, and presented with a different of concerns; $73 \%$ were low septae, $18 \%$ were mid-vaginal, and $9 \%$ were high; $55 \%$ were managed with a vaginal approach, $27 \%$ were managed with an abdominoperineal approach, and $18 \%$ had laparoscopic resection; $10 \%$ of patients presented with reobstruction, all following abdominoperineal vaginoplasty; following the abdominoperineal approach. These results showed that $10 / 12$ patients were menstruating, $66 \%$ had been sexually active, $34 \%$ had dyspareunia, and $37 \%$ complained of dysmenorrhoea. There were 3 pregnancies, with one abortion and 2 live births, three following the vaginal approach and one following laproscopic excision of a transverse vaginal septum. Conclusions: Transverse vaginal septae resected vaginally/laparoscopically have low complication rates and good long-term outcomes. Complex septae require more extensive surgery, with an increased risk of complications.

Key Words: Obstructed menstruation, primary amenorrhoea, transverse vaginal septum, vaginal agenesis.
\end{abstract}

*Address for Correspondence:

Dr Monali Ashok Sonone, Post Graduate Resident, Department of Obstetric And Gynaecology, Smt. Kashibai Navale Medical College And Hospital, Narhe,Pune, Maharashtra, INDIA.

Email: dr.monaliasonone $a$, gmail.com

Received Date: 05/04/2020 Revised Date: 13/05/2020 Accepted Date: 28/07/2020

DOI: https://doi.org/10.26611/10121538

This work is licensed under a Creative Commons Attribution-NonCommercial 4.0 International License. (oc)) EY-NC

\begin{tabular}{|l|l|}
\hline \multicolumn{2}{|c|}{ Access this article online } \\
\hline Quick Response Code: & Website: \\
\hline & www.medpulse.in \\
& \\
\hline
\end{tabular}

\section{INTRODUCTION}

A rare type of mullerian anomaly is Transverse vaginal septae. The exact incidence is not known, but it is between $1 / 2100$ and $1 / 72000^{1}$. Transverse vaginal septae are thought to be a result of failed canalisation of the vaginal plate at the point where the urogenital sinus meets the Mullerian duct. Vaginal Septae can be perforate or imperforate, and they vary in their thickness and also with location in the vagina. Septa are most commonly imperforate and manifest as primary amenorrhea, abdominal pain, and hematocolpos in adolescence. Perforate septa have a more variable presentation, usually associated with the foreshortened vagina and can present in adolescence or young adulthood. Imperforate septae seen in adolescence with obstructed menstruation and haematocolpos. On other hand Women with a perforate septum often have normal menses and usually present with difficulties with intercourse or tampons. The risk of endometriosis increases with imperforate septa that are located higher in the vagina. Proper diagnosis preoperative planning can be made with history, clinical examination, ultrasound, and magnetic resonance imaging $(\mathrm{MRI})^{1}$. Treatment for transverse vaginal septum involves surgical resection of the septum and anastamosis of the proximal and distal vaginas. This can be performed vaginally, laparoscopically, or through an 
abdominoperineal approach, treatment highly depending on the location and thickness of the septum ${ }^{8,3}$. Accurate information on the septum is available to ensure that the correct operative approach is chosen is essential. The patient's age, developmental level, and ability to perform postoperative dilation should be considered when exploring surgical options, since prolonged dilation is often indicated in the postoperative period. There is little guidance available in the medical literature regarding either the classification of transverse vaginal septae or the choice of surgical technique, however. In addition, there is scanty published data on short- or long-term outcomes following the resection of transverse vaginal septae. Complications after surgery include vaginal stenosis and reobstruction (recurrence), dyspareunia, endometriosis, infertility, obstetric complications, and psychological difficulties. The aim of this study was to describe the presentation, assessment, treatment, and outcomes in 22 girls and women with a congenital transverse vaginal septum.

\section{METHODS}

This was an observational study performed in Tertiary referral centre SMT KASHIBAI NAVALE MEDICAL COLLEGE and HOSPITA, Narhe, Pune. Population of 22 girls and women with a transverse vaginal septum. Patients were identified from the departmental surgical database, and all patients presenting with a diagnosis of transverse vaginal septum between 2012 and 2019 were included in the study.

1. All medical records were reviewed for information regarding clinical presentation, vaginal examination, imaging, including magnetic resonance imaging (MRI) and ultrasound, surgical management, short-term and long-term complications, and the need for dilation therapy;

2. History from data was collected regarding menstruation, sexual intercourse, fertility and pregnancy details.

Septae were categorised using local protocol, by location, thickness and presence or absence of a perforation.

Table 1: classification of vaginal septae

\begin{tabular}{|c|c|}
\hline Location & \\
\hline \multirow{3}{*}{$\begin{array}{l}\text { (Distance from vaginal introitus to the distal } \\
\text { end of septum) }\end{array}$} & Low $<3 \mathrm{~cm}$ \\
\hline & Mid 3-6cm \\
\hline & $\mathrm{High}>6 \mathrm{~cm}$ \\
\hline \multirow[t]{2}{*}{ Thickness } & Thick >1cm \\
\hline & Thin $<1 \mathrm{~cm}$ \\
\hline \multirow[t]{2}{*}{ Perforation } & Perforated \\
\hline & Imperforated \\
\hline
\end{tabular}

The location is based on the distance from the vaginal introitus to the distal end of the septum. In the collected data the detailed clinical examination was mentioned this assessment was possible with vaginal examination in the clinic, but in younger patients an examination under anaesthesia was required. The method for examination considered was the upper margin of the septum was the distal end of the proximal obstructed vagina, and this is easily visualised. The proximal margin of the distal vagina was identified as being the most proximal margin of normal vaginal mucosa and secretions as determined on transverse and sagittal T2-weighted images. The thickness of the septum was measured as the distance between these two observed markers. All MRIs were reported by a consultant radiologist.

\section{RESULTS}

There were 22 cases of transverse vaginal septae managed throughout the study period. 14(64\%) were imperforate, and presented with obstructed menstruation. 8 (20\%) presented with an inability to insert tampons, have sexual intercourse, or have smears. The mean age at presentation for obstructed septae was 15.5 years, and for nonobstructed septae was 23 years, with an overall average age of 18.3 years. 5 patients $(23 \%)$ had a history of a previous unsuccessful operation for menstrual obstruction prior to referral to our specialist unit. 4 had incision and drainage only, and 1 had septum resection, with all patients presenting with reobstruction. 15/22 patients (69\%) had magnetic resonance imaging (MRI) as part of their investigative work-up, either in the referring hospital or in our tertiary care centre. All patients with obstructed menstruation were either already on or were prescribed menstrual suppression, with either continuous combined oral contraceptive (COCP) or gonadotrophin-releasing hormone analogues(GnRHas) prior to their definitive procedure. $16(73 \%)$ of the septae were low, $4(18 \%)$ were in the mid-vagina, and $2(9 \%)$ were high.

Surgical management

\section{Abdominoperineal approach}

6 patients $(27 \%)$ were managed with abdominoperineal vaginoplasty via laparotomy. All of these septae were imperforate. 1patients $(17 \%)$ had undergone previous surgery for the septum in the referring hospital. There were no long-term consequences following this. Other complications were a wound infection, pyometra. 5/6 patients $(83 \%)$ were asked to use vaginal dilation following abdominoperineal vaginoplasty. One patient had severe learning difficulties and so was unable to dilate, but had normal periods following surgery. 2 patients (33\%) re-presented with recurrent menstrual obstruction, and $1(17 \%)$ re-presented with dysmenorrhoea (although this 
was thought to be secondary to endometriosis, rather than vaginal stenosis).

\section{Vaginal approach}

$12(55 \%)$ patients were operated upon using a vaginal approach, including all of the perforate septae. 10patients $(83 \%)$ underwent a simple excision of the septum, but 2 $(17 \%)$ required rotation of perineal skin flaps to bridge the vaginal defect and ensure a normal calibre vagina. There were no short-term complications in this group. 4 out of 12 patients $(33 \%)$ were asked to perform vaginal dilation after surgery. This was recommended in cases where skin flaps were used and where there was significant scarring from previous surgery. There was 1 cases of vaginal stenosis $(8 \%)$, which were treated by vaginal dilation therapy.

\section{Laparoscopic resection}

$4(18 \%)$ had a laparoscopic resection of a transverse vaginal septum. In these patients the septae were high $/ \mathrm{mid}$, thick $(<2 \mathrm{~cm})$, and imperforate. All patients had undergone previous surgery in their referring hospital but reobstructed. There were no short- or long-term complications in this group. All patients were advised to dilate following surgery. Endometriosis 1 of these patients (25\%) had documented evidence of endometriosis. All septae were imperforate.

\section{Long-term outcomes}

The median length of follow-up after surgery was 10 months (ranging from 6 weeks to 3 years). 5/8 (63\%) had been sexually active. 1 patients $(13 \%)$ described dyspareunia. 1 patient was found to have vaginal stenosis, which was treated with vaginal dilation therapy. 8/ 22 patients $(36 \%)$ complained of dysmenorrhoea requiring analgesia. There were 3 pregnancies, 2deliveries and 1 spontaneous abortion, All pregnancies were in the group who had vaginal excision of transverse vaginal septum, as the septae were all thin.

\section{DISCUSSION}

Transverse vaginal septae have been classified as low, medium, or high depending upon their position in the vagina. The European Society of Human Reproduction and Embryology (ESHRE) and the European Society for Gynaecological Endoscopy (ESGE) have developed a new classification system for Mullerian anomalies, in which transverse vaginal septae are assigned to subclass V3; however, transverse vaginal septae are not classified any further within this new classification system ${ }^{4}$. The largest series in the literature reported 26 imperforate septae, and classified these as being in the lower, middle, or upper third of the vagina ${ }^{8}$. This may arise from the different methods of classification. The only other large published series available is a literature review of 19 case reports, which included 73 patients with transverse vaginal septae $e^{(5)}$. Thickness of transverse vaginal septae is important for surgical management, and therefore the short-term and long-term outcomes. It is accepted that low thin septae and thin perforate septae are less complex, and can be resected vaginally with a low complication rate. It is important that the entire septum is resected to prevent re-stenosis and scarring. Obstructed, mid, high, and thick septae are more complex, as approaching a mid or high septum blindly though the vagina increases the risk of trauma to adjacent organs. Thick septae may be difficult to remove and may leave a defect in the vagina between the proximal and distal vaginas. Insertion of a skin graft onto scarred skin is unlikely to be successful. The potential requirement for grafting should be determined in advance of the procedure to allow informed consent and appropriate preparation for surgery. MRI is widely used to delineate pelvic anatomy, and has been found to correlate well with clinical findings when assessing Mullerian and vaginal anomalies ${ }^{2,7}$. We have previously reported on the laparoscopic resection of transverse vaginal septae. It is a safe and effective technique in a select number of patients where a laprotomy would otherwise be required ${ }^{3}$. Septae that are mid or high, $<2 \mathrm{~cm}$ thick, with an adequately distended proximal vagina, and no other complex pelvic anomalies are suitable for laparoscopic resection. Where the septum is $>2 \mathrm{~cm}$ in thickness there is a possibility that a bowel segment may be required to bridge the gap between the proximal and distal vaginas. In these patients, an abdominoperineal approach is recommended. Abdominoperineal vaginoplasties often involve complex reconstructive surgery, and therefore long-term complications such as reobstruction and fistulae are more common ${ }^{9}$. Our data demonstrated good short-term outcomes for all low a and perforate transverse septae. In the study of transverse vaginal septae by Rock et al.., the re-stenosis rate was not discussed $^{(2)}$. The only other available data are from a retrospective study of presentation and long-term outcomes of obstructive vaginal anomalies. This study contained only three patients of transverse vaginal septae, which were low and mid, and all imperforate. Thickness was not described. Two out of the three septae developed vaginal stenosis requiring re-excision ${ }^{(10)}$. Patients and surgeons need to be aware of the complexity and risks involved in managing mid or high, thick septae. Rock et al. showed a significantly reduced chance of conception following resection of transverse vaginal septum, compared with imperforate hymen, and mid and high septae had a lower chance of conception than low septae ${ }^{2}$. The cause for this has not yet been determined and vaginal stenosis may be a contributory factor; however, they also reported similarly high rates of endometriosis in mid and 
high septae. The incidence of endometriosis in the general population is approximately $10 \%{ }^{11}$ and this is known to be significantly increased in obstructed Mullerian anomalies thought to be secondary to retrograde menstruation ${ }^{12}$. Corrective surgery for the obstructed anomaly has been found to result in the complete resorption of the endometriosis ${ }^{13}$. Previous studies have suggested that patients with a high transverse vaginal septum have a higher incidence of endometriosis, compared with mid and low septae ${ }^{(2)}$.We have found a higher incidence in thick septae, which have a shorter proximal vagina and therefore less distensible space for obstructed menstrual blood, perhaps increasing retrograde menstruation. Vaginal dilation is usually recommended after reconstructive vaginal surgery to maintain vaginal capacity and prevent stenosis or reobstruction ${ }^{9}$ although there is little evidence base to support this. Dilation is recommended in all patients following laparoscopy or laparotomy, and invaginal patients where skin flaps have been used or if there is significant scarring. Dilation should commence within a few days of surgery. If compliance is poor, there is an increased risk of reobstruction requiring more complex reconstructive surgery. In this study reobstruction was significantly more likely in women who could not or would not dilate. Dilation is often described by women as uncomfortable, time-consuming, and a constant reminder of their abnormality ${ }^{14}$. It is imperative that the patients are enrolled in a dedicated dilation programme, with support from a clinical nurse specialist and psychologist.

\section{Strengths and limitation}

This study involves location of septae low, mid vaginal septae, high and also this involves perforated or imperforated septae, different surgical approach for management of transverse vaginal septum. The main drawback of this study is that it is a retrospective review; however, given the rarity of this condition, this study likely to be representative of this unusual condition, and the study does provide useful data. knowledge of the type of septum allows the prediction of the likelihood of success and risk of complications.

\section{CONCLUSION}

This study shows that transverse vaginal septae that are suitable for vaginal or laparoscopic resection are associated with low complication rates and good reproductive outcomes. More complex septae require more extensive reconstructive surgery, with an increased risk of complications. Further long-term studies are required to fully assess the long-term reproductive outcomes following resection of transverse vaginal septae.

\section{REFERENCES}

1. Saks EK, Vakili B, Steinberg AC. Primary amenorrhoea with an abdominal mass at the umbilicus. J Pediatr Adolesc Gynaecology 2009;22:e1-3.

2. Humphries PD, Simpson JC, Creighton SM, Hall-Craggs MA. Magnetic resonance imaging for the assessment of congenital vaginal anomalies. Clin Radiol 2008;63:442-8.

3. Williams CE, Cutner A, Creighton SM. Laparoscopic management of high transverse vaginal septae: a case report. Gynecol Surg 2013; 10:189-91.

4. Grimbizis GF, et al.. The ESHRE/ESGE consensus on the classification of female genital tract congenital anomalies. Hum Reprod 2013;28:2032-44.

5. Levy G, Warren M, Maidman J. Transverse vaginal septum: case report and review of the literature. Int Urogynecol J 1997;8:173-6.

6. McIndoe A. The treatment of congenital absence and obliterative conditions of the vagina. $\mathrm{Br} \mathrm{J}$ Plast Surg 1950;2:254-67.

7. Creighton SM, Hall-Craggs MA. Correlation or confusion: the need for accurate terminology when comparing magnetic resonance imaging and clinical assessment of congenital vaginal anomalies. J Pediatr Urol 2012;8:17780 .

8. Rock JA, Zacur HA, Dlugi AM, Jones HW, TeLinde RW. Pregnancy success following surgical correction of imperforate hymen and complete transverse vaginal septum. Obstet Gynecol 1982;59:448-51.

9. Davies MC, Creighton SM, Woodhouse CRJ. The pitfalls of vaginal construction. BJU Int 2005;95:1293-8.

10. Joki-Erkkila MM, Heinonen PK. Presenting and long-term clinical implications and fecundity in females with obstructing vaginal malformations. J Pediatr Adolesc Gynecol 2003;16:307-12.

11. Vigano P, Parazzini F, Somigliana E, Vercillini P. Endometriosis: epidemiology and aetiological factors. Best Pract Res Clin Obstet Gynaecol 2004;18:177-200.

12. Olive DL, Henderson DY. Endometriosis and mullerian anomalies. Obstet Gynecol 1987;69:412-15.

13. Sanfilippo JS, Wakim NG, Schikler KN, Yussman MA. Endometriosis in association with uterine anomaly. Am J Obstet Gynecol 1986;154:39-43.

14. Liao LM, Doyle J, Crouch NS, Creighton SM. Dilation as treatment for vaginal agenesis and hypoplasia: a pilot exploration of benefitsand barriers as perceived by patients. J Obstet Gynaecol 2006;26:144-8.

\section{Source of Support: None Declared Conflict of Interest: None Declared}

Policy for Articles with Open Access:

Authors who publish with MedPulse International Journal of Gynaecology, (Print ISSN: 2579-0870) (Online ISSN: 2636-4719) agree to the following terms: Authors retain copyright and grant the journal right of first publication with the work simultaneously licensed under a Creative Commons Attribution License that allows others to share the work with an acknowledgement of the work's authorship and initial publication in this journal.

Authors are permitted and encouraged to post links to their work online (e.g., in institutional repositories or on their website) prior to and during the submission process, as it can lead to productive exchanges, as well as earlier and greater citation of published work. 